\title{
A case report of disseminated cysticercosis in Bali, Indonesia
}

\author{
A.A.Raka Sudewi ${ }^{1}$, Toni Wandra ${ }^{2 *}$, Oka Adnyana ${ }^{1}$, Moestikaningsih ${ }^{3}$, A.A.B.N. Nuartha ${ }^{1}$ \\ Yasuhito Sako ${ }^{4}$, Kazuhiro Nakaya ${ }^{5}$, Akira Ito $^{4}$ \\ ${ }^{1}$ Department of Neurology, Faculty of Medicine, University of Udayana, Bali \\ ${ }^{2}$ Sari Mutiara Indonesia University, Medan, North Sumatra \\ ${ }^{3}$ Department of Pathology Anatomy, Faculty of Medicine, University of Udayana, Bali \\ ${ }^{4}$ Department of Parasitology, Asahikawa Medical College, Asahikawa, Japan \\ ${ }^{5}$ Animal Laboratory for Medical Research, Asahikawa Medical College, Asahikawa, Japan
}

\begin{abstract}
We reported the case of a 36-year-old Balinese man who disseminated cysticercosis, presented neuro-, subcutaneous- and oral-cysticercosis. Diagnosis of it was based on anamnesis, clinical examination including CT Scan, histopathological and serological examinations. The patient visited outpatient clinic of Sanglah Denpasar Hospital in Bali, in June 2003 with two subcutaneous nodules in the body. Serological examinations (ELISA and immnunoblot) used both purified glycoproteins and chimeric recombinant antigen were positive. The two subcutaneous nodules disappeared after treatment with albendazole. In January 2004, the patient presented neuro-, and oral-cysticercosis. CT Scan showed multiple active lesions in the brain. During the treatment with 800 $\mathrm{mg}$ albendazole daily during for one month. The side effects of it such as nausea and vomit were found in that patient. Antibody responses in ELISA and immnunoblot were still positive and follow up CT scan in May 2004, it showed that very similar figures as previously. Repeated treatment with $400 \mathrm{mg}$ albendazole daily for one and half month was applied. Antibody responses became low, and CT scan in March 2006 did not show any active cysts but only calcified lesions.
\end{abstract}

Keywords: disseminated cysticercosis, neurocysticercosis, subcutaneous cysticercosis, oralcysticercosis, Taenia solium, Bali, Indonesia

"Corresponding author: Toni Wandra,

Tel.: 081388422934

E-mail: tony_wdr2009@yahoo.com

\section{BACKGROUND INFORMATION ON TAENIASIS/CYSTICERCOSIS}

Taenia solium is a human tapeworm which can cause two distinct clinical presentations : taeniasis by the presence of adult tapeworm (s) in the small intestine, and cysticercosis by the presence of larval stage in the tissues including brain, muscle, eyes etc. The life cycle of this parasite completes between humans and mainly pigs ${ }^{1,2}$. By consuming uncooked or undercooked pork contaminated with metacestodes (=cysticercus/cysticerci) of $T$. solium, human gets infection with the metacestodes, which become adult tapeworms in the small intestine within a few months. Eggs in faeces from tapeworm carriers contaminate the environment. Usually such eggs or proglottids are ingested by the main intermediate host, pigs and even dogs ${ }^{3}$.

In humans, the ingestion of eggs of $T$. solium happens through contaminated such as food, vegetable and water. It is also due to auto-infection, directly through anal-oral route through contaminated hands etc., or internal auto-infection, by reflux of the proglottid or eggs from the intestine into the stomach $4,5,6$. Cysticecosis can affect many anatomical areas, but it becomes more prominent in central nervous system (CNS) causing neurocysticercosis (NCC). NCC is the most common parasitic disease of the CNS and one of the most important causes of epilepsy ${ }^{6,7}$.

In this report we describe a patient of disseminated cysticercosis, who presented neuro-, subcutaneous-, and oralcysticercosis.

\section{CASE REPORT}

A 36-year-old Balinese man, from a rural village of Sukawati Sub-District, Gianyar District, southtern part of Bali, Indonesia visited outpatient clinic of Sanglah hospital, Denpasar, Bali, in June 2003. He presented two subcutaneous nodules, the first nodule was recognized for about five years located at left lower arm, while the second nodule for about 
one year at left ear. Through general examination, it was revealed that these two nodules were located in subcutaneous tissues and mobile with no tender, with about $1 \mathrm{~cm}$ of diameter each. Serological examinations using native and recombinant antigens for detection of active cysticercosis (ELISA and immnunoblot) ${ }^{8,9,10,11,12}$, were positive (Fig. 2, 3).

Fig. 1. CT Scan performed 3 months (in May 2004) after treated with albendazole (from January to February 2004) showing active lesions (white arrow) as previously finding in January 2004 (A). Repeated CT Scan performed in March 2006 showed calcified lesions (black arrow) (B).
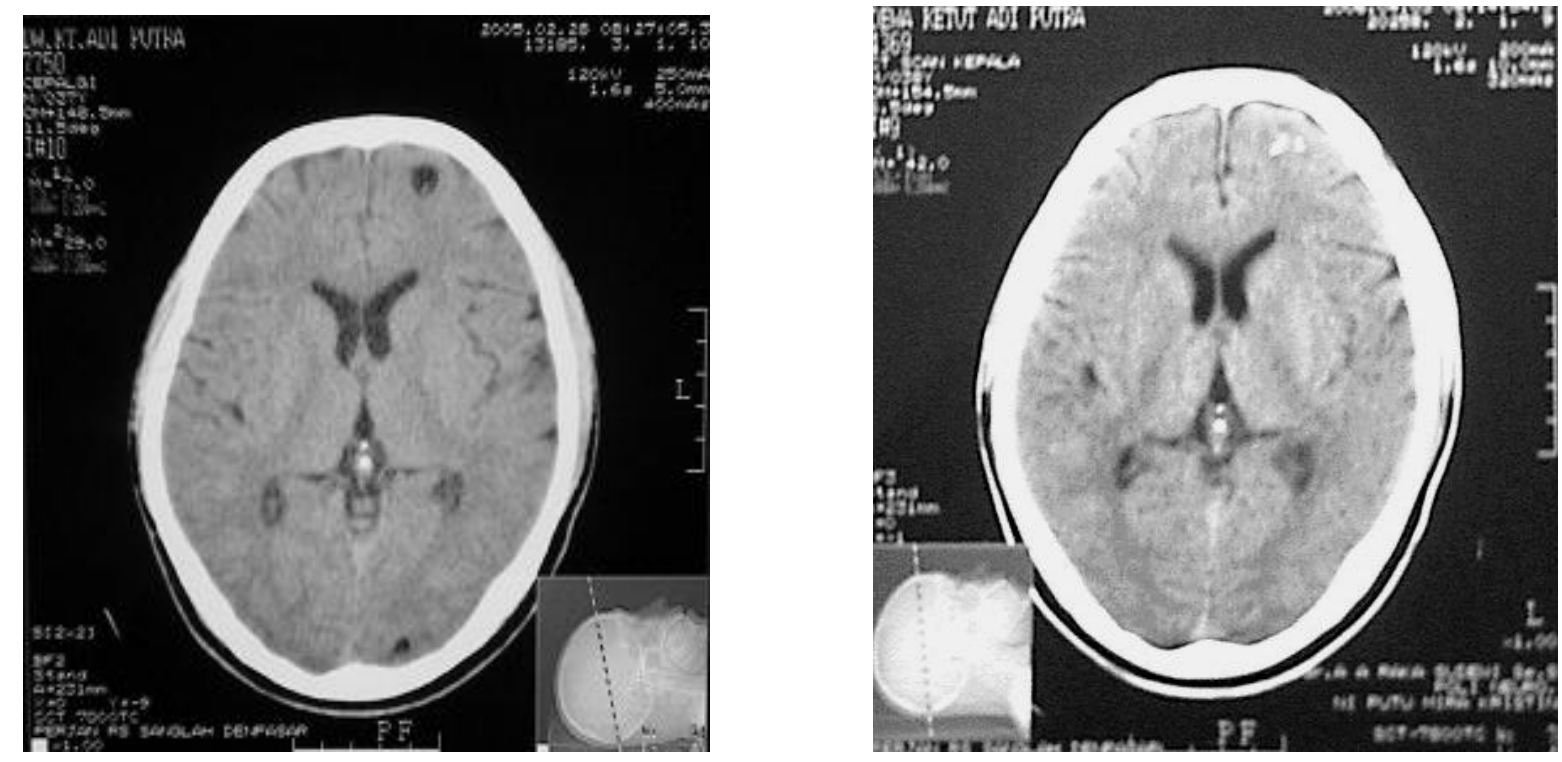

Fig. 2. ELISA optical density (OD) of 3 serial serum samples of patient in June 2003 (a), February 2004 (b) and February 2006 (c) using native ( ) and recombinant (•) antigens.

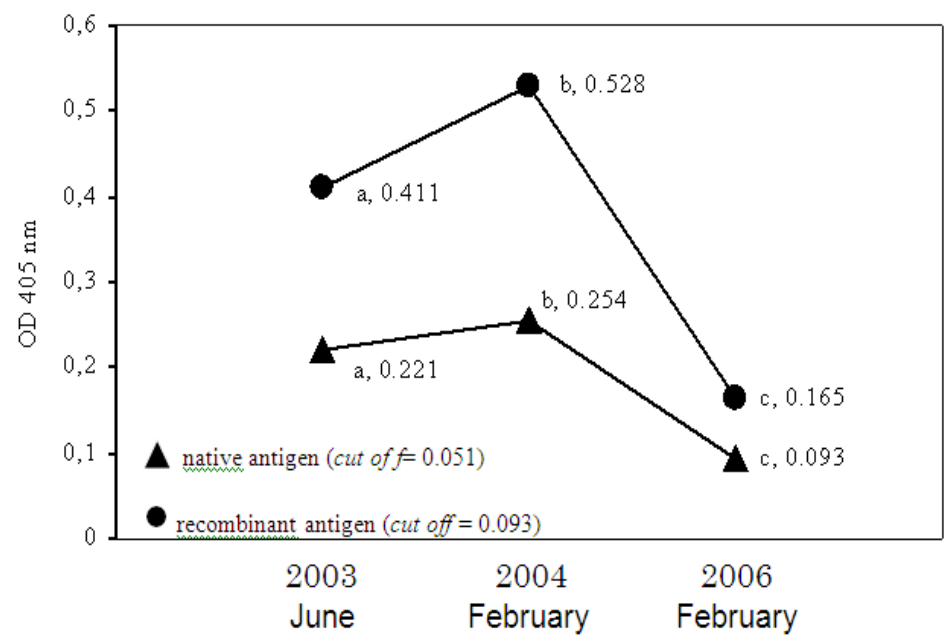

Collected serum sample years and months 
Fig. 3. Immunoblot analysis of 3 serial serum samples of patient in June 2003 (a), February 2004 (b) and February 2006 (c). Lane (p): positive control. Lane $(\mathrm{n})$ : negative control. All serum samples were examined under 1/20 dilution. Serum samples showing even single band of these specific bands using native antigen (approximately between 10 and 50 $\mathrm{kDa}$ ) or using recombinant antigen (18kDa) was diagnosed serologically as cysticercosis.

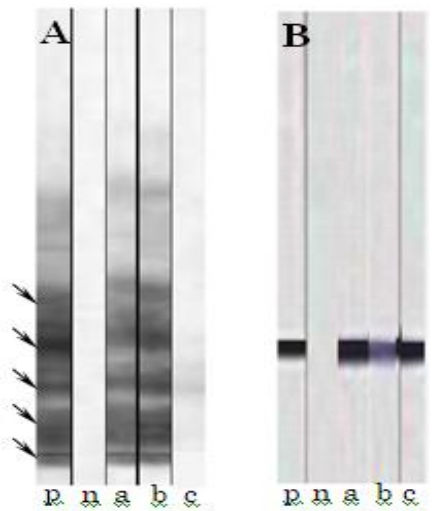

Fig. 4. T. solium cysticercus resected from tongue of patient. Spiral canal (Sc) was seen in the center of neck region $(\mathrm{N})$ which was surrounded by bladder wall (Bw). Scolex or vesicular chamber was not observed. Whole cysticercus was surrounded with host granulomatous reaction (G). Bar=500 $\mu \mathrm{m}$

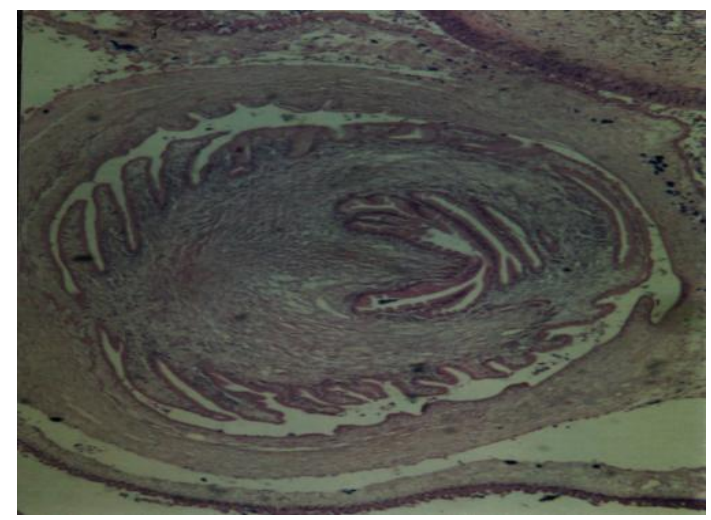

The second visit to the hospital was in January 2004. The patient complained of headache, history of epileptic seizures for six month duration, and the presence of a painless swelling on the tongue. However the two subcutaneous nodules disappeared after treatment with albendazole at the first visit in 2003. There was no abnormality in respiratory and cardiovascular systems. A detailed neurological examination revealed unremarkable findings. Laboratory data including routine blood tests were normal.

CT Scan showed multiple active lesions on frontalis sinistra, parieto ocipital region (figures not shown). An excision of the nodule about $0.5 \times 0.5 \times 0.5 \mathrm{~cm}$ was performed in the tongue. Histopathological examination revealed a characteristic structure of taeniid cysticercosis with granulomatous reaction (Fig. 4).

The patient was treated with $800 \mathrm{mg}$ daily albendazole for one month and 40 $\mathrm{mg}$ of dexamethason orally for a week, from January to February 2004. OD values in ELISA using both native/recombinant antigens increased from $0.221 / 0.411$, to $0.254 / 0.528$ (cut off $=0.051 / 0.093$ ) (Fig. 2) and immunoblot showed strong responses (Fig. 3). CT Scan in May 2004 still showed active lesions as previously (Fig. 1). During this treatment the patient did not take albendazole regularly due to nausea and vomit, but headache was rare and he became free of seizures. Repeated treatment was performed with $400 \mathrm{mg}$ daily albendazole for 1.5 month in 2005 . He appeared to be clinically asymptomatic. OD value in ELISA in February 2006 decreased to $0.093 / 0.165$ and immunoblot using native antigen showed weak reaction (Fig. 2, 3). The third CT scan carried out in March 2006 did not show active cysts but only calcified lesions (Fig 1).

\section{DISCUSSION}

Diagnostic criteria for disseminated cysticercosis are based on the presence of multiple cysticercosis showing NCC-, SCC- and oral-cysticercosis (OCC) simultaneously. Pathological examination for final dianosis of SCC is the investigation of choice (Foyaca-Sibat et al., 2004). In this case, physical examination, serologic examination for cysticercosis, changes observed on the nodular lesions after treatment with albendazole, and the resected nodule (Fig. 4) supported the diagnosis.

OCC alone is considered to be rare and differential diagnosis of oral lesion depends on the site involved ${ }^{13}$. Based on histopathological examination (Fig. 4), we 
diagnosed this patient as OCC. However, there is no report on OCC or NCC and/or SCC with OCC simultaneously in Indonesia so far.

We found the lesions highly suggestive of NCC based on CT scan, serological positive results, history of epileptic seizures, cysticercosis outside the CNS, and the patient who like living in the area where cysticercosis is still endemic, so that we made diagnosis of $\mathrm{NCC}^{14}$.

During treatment in 2004, the patient did not take albendazole regularly due to nausea and vomit, and the second CT Scan in 2004 showed the very similar figures as in 2003. However, headache was rare and he was free of seizures. After repeated treatment with albendazole, he was clinically asymptomatic and ELISA and immunoblot showed extremely weak reactions (Fig. 2, 3). We did immunoblot (IB) using recombinant antigen. The antibody responses in $1 / 20$ dilution of serum samples were too strong compared with many bands of native antigens responding with antibodies. However, we had no more serum samples for showing the drops in titters by IB. The third CT scan in March 2006 showed calcified lesions only without active cysts (Fig 1).

Considering such side effects as nausea and vomit when the patient took albendazole with $800 \mathrm{mg}$ daily, we reduced to $400 \mathrm{mg}$ of daily dose for one and half month. Then the patient had no more nausea and vomit. We did not try to re-treat with praziquantel, since we had poor experience on the treatment with this drug especially for the case with disseminated cysticercosis.

\section{ACKNOWLEDGEMENT}

We are grateful to all staffs at Department of Parasitology, Asahikawa Medical College for technical assistance, and the Head and staffs of Department of Neurology, University of Udayana, Bali, for their cooperation and assistance in the study. This work was supported by Japan Society for Promotion of Science (JSPS) to A.I. (17256002).

\section{REFERENCES}

1. Ito, A., Nakao, M., Wandra, T., 2003. Human taeniasis and cysticercosis in Asia. The Lancet 362, 1918-20.

2. Ito, A., Wandra, T., Yamasaki, H., Nakao, M., Sako, Y., Nakaya, K., Margono S.S., Suroso, T., Gauci, C., Lightowlers, $\quad$ M.W., 2004. Cysticercosis/taeniasis in Asia and the Pacific Vector-Borne Zoonotic Dis. 4, 95-107.

3. Ito, A., Putra, M.I., Subahar, R., Sato, M.O., Okamoto, M., Sako, Y., Nakao, M., Yamasaki, H., Nakaya, K., Craig, P.S., Margono S.S., 2002. Dogs as alternative intermediate hosts of Taenia solium in Papua (Irian Jaya), Indonesia confirmed by highly specific ELISA and immunoblot using native and recombinant antigens and mitochondrial DNA analysis. J. Helminthol. 76, 311-4.

4. Bakta, I.M., 1989. Taeniasis. IImu penyakit dalam (internal medicine). Balai Penerbit FKUI, Jakarta. I ( $2^{\text {nd }}$ edition), 87-92 (in Indonesia).

5. Subianto, D.B., Tumada, L.R., Margono, S.S., 2006. Burns and epileptic fits associated with cysticercosis in mountain people of Irian Jaya. Trop. Geogr. Med. 30, 275-8.

6. F.A.O., 2003. Food and Agriculture Organitation of the United Nations, and created and designed at Brock University St. Catharines, Canada. The tutorial Taenia solium: A common parasite affecting global health, version 1.0.

7. Takayanagui, O.M. and Odashima, N.S., 2006. Clinical aspects of neurocysticercosis. Parasitol. Internat. 55 Suppl, S111-S115.

8. Ito, A., Plancarte, A., Ma, L., Kong, Y., Flisser, A., Cho, S.Y., Liu, Y.H., Kamhawi, S., Lightowlers, M.W., Schantz, P.M., 1998. Novel antigens for neurocysticercosis: a simple method for preparation and evaluation for serodiagnosis. Am. J. Trop. Med. Hyg. 59, 291-294.

9. Ito, A., Nakao, M., Ito, Y., Yuzawa, I., Morishima, H., Kawano, N., Fujii, K., 
1999. Neurocysticercosis case with a single cyst in the brain showing dramatic drop in specific antibody titers within 1 year after curative surgical resection. Parasitol. Internat. 48, 95-99.

10. Sako, Y., Nakao, M., Ikejima, T., Piao, X.Z., Nakaya, K., Ito, A., 2000. Molecular characterization and diagnostic value of Taenia solium low-molecular-weight antigen gene. J. Clin. Microbiol. 38, 4439-4444.

11. Sako, Y., Nakao, M., Nakaya, K., Yamasaki, H., Ito, A., 2006. Recombinant antigens for serodiagnosis of cysticercosis and echinococcosis. Parasitol. Internat. 55 Suppl, S69-S73.

12. Sato, M.S., Sako, Y., Nakao, N., Yamasaki, Y., Nakaya, K., Ito, A., 2006. Evaluation of purified Taenia solium glycoproteins and recombinant antigens in the serologic detection of human and swine cysticercosis. J Inf Disaeses, inpress.

13. Elias, F.M., Martin, M.T., Foronda, R., Jorge, W.A., Araújo, N.S., 2005. Oral cysticercosis: case report and review of the literature. Article in Mar/Apr 2005 issue of Rev. Inst. Med. Trop. S Paulo.

14. Del Brutto, O.H., Rajshekhar, V., White, A.C., Tsang, V.C.W., Nash, T.E., Takayanagui, O.M., Schantz, P.M., Evans, C.A.W., Flisser, A., Correa, D., Botero, D., Allan, J.C., Sarti, E., Gonzalez, A.E., Gilman, R.H., García, H.H., 2001. Proposed diagnostic criteria for neurocysticercosis. Am. Acad. Neurol. 57, 177-183. 